\title{
Potential dependent electrochemical exfoliation of NiPS3 and implications for hydrogen evolution reaction
}

\author{
Jan Luxa ${ }^{a}$, Štěpán Cintla ${ }^{\mathrm{a}}$ Lucie Spejchalováa, Jeng-Yu Lin ${ }^{\mathrm{b}}$ and Zdeněk Sofer ${ }^{* a}$
}

a. Department of Inorganic Chemistry, University of Chemistry and Technology Prague, Technická 5, 16628 Prague 6, Czech Republic

e-mail: zdenek.sofer@vscht.cz

b. Department of Chemical Engineering and Biotechnology, Tatung University, No. 40, Sec. 3, Chungshan North Rd., Taipei City 104, Taiwan

Supporting Information

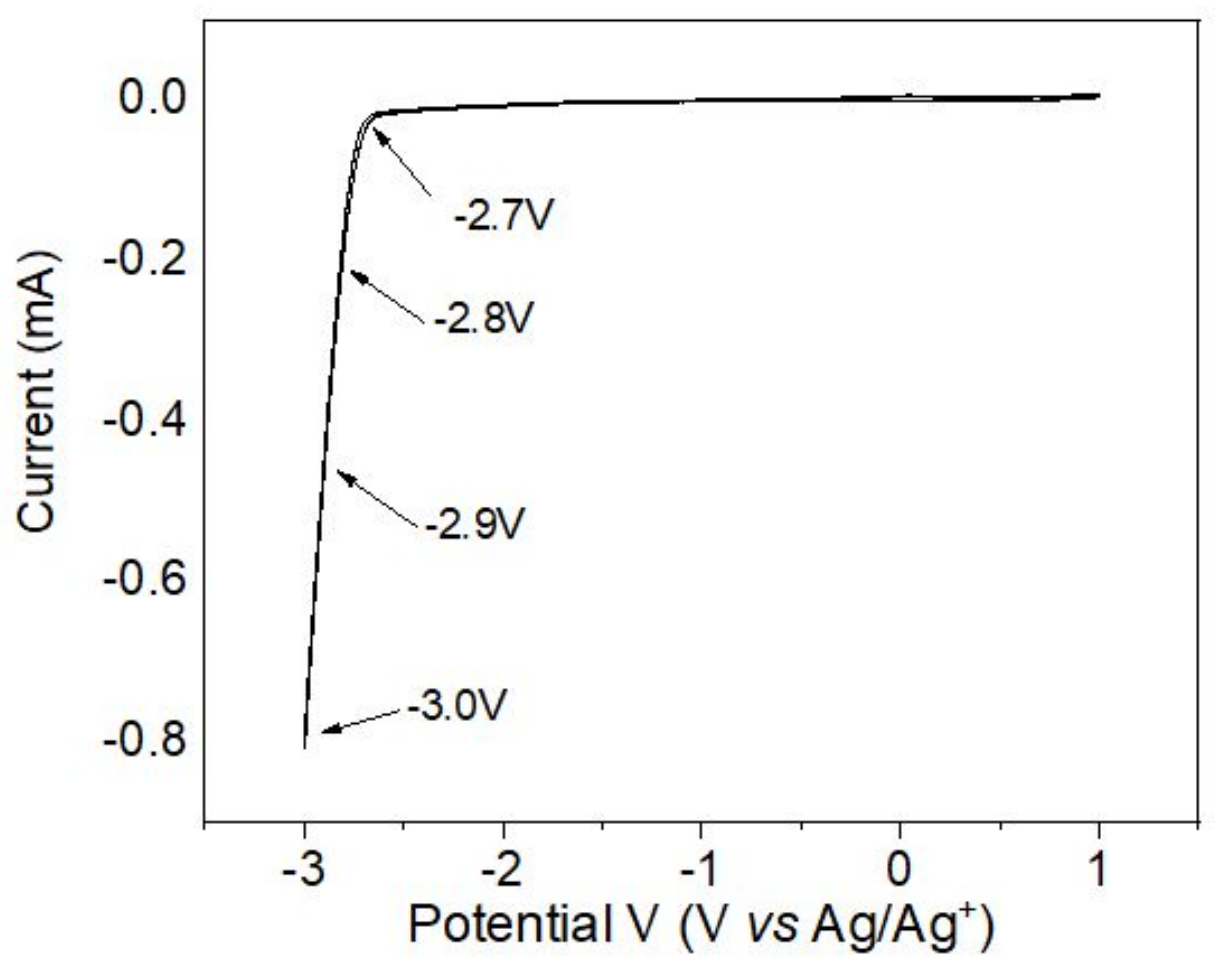

Figure S1. The potential window of the electrolyte (o.1M tetra-buthylammonium hexafluorophosphate in acetonitrile) used for electrochemical exfoliation. 


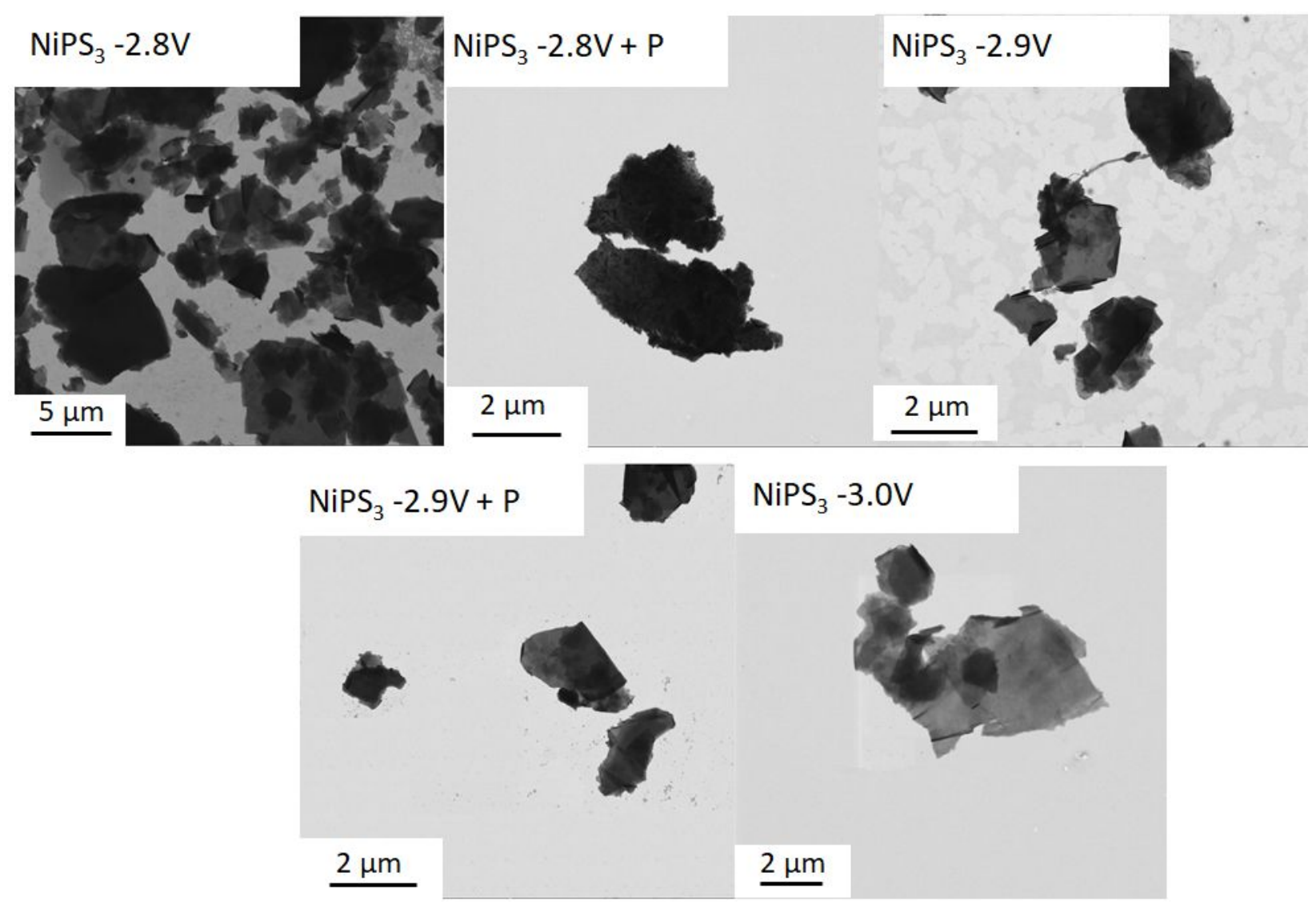

Figure S2. Scanning transmission electron microscopy images of $\mathrm{NiPS}_{3}$ samples exfoliated at various potentials. 


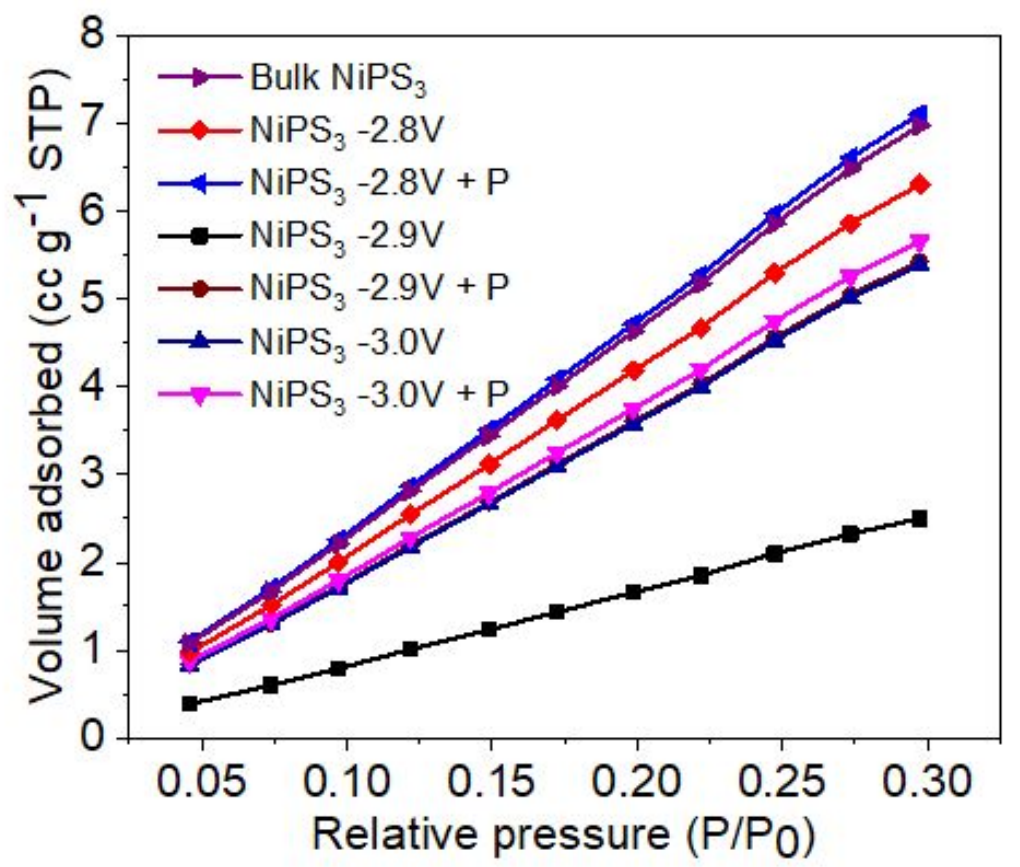

Figure S3. Adsorption isotherms used for the evaluation of surface areas by means of Brunauer-Emmet-Tellet (BET) measurements at the temperature of liquid nitrogen $(77 \mathrm{k})$. 

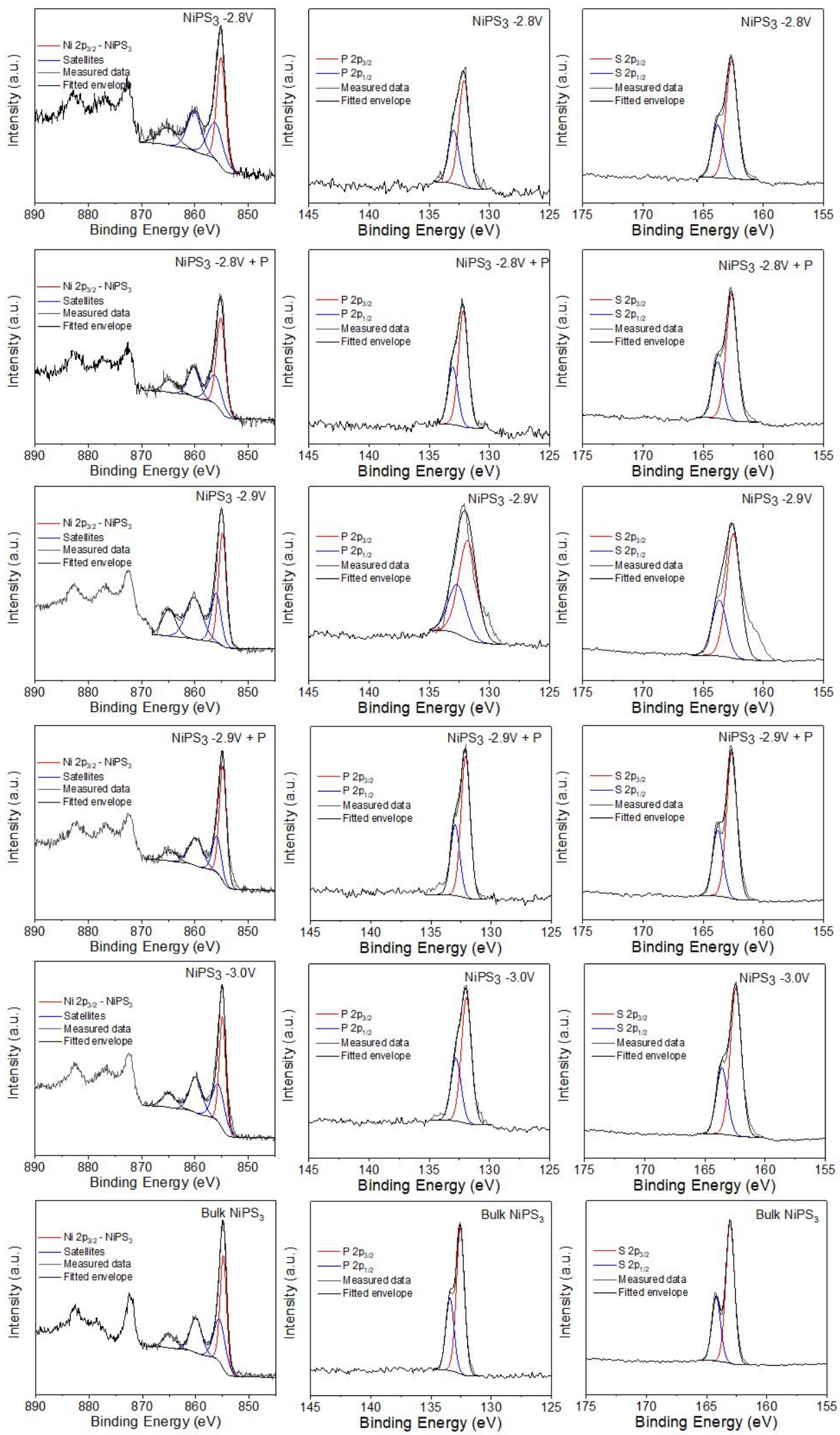

Figure $\mathrm{S}_{4}$. X-ray photoelectron spectra showing $\mathrm{Ni}$ 2p, $\mathrm{P} 2 \mathrm{p}$ and $\mathrm{S} 2 \mathrm{p}$ regions in $\mathrm{NiPS}_{3}$ samples exfoliated at various potentials. 


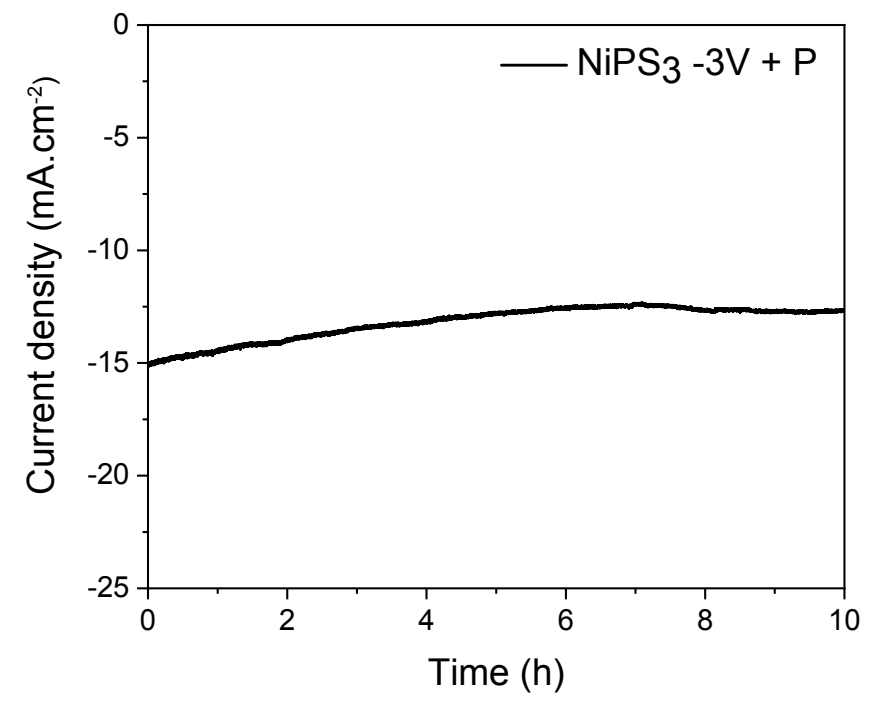

Figure $\mathrm{S}_{5}$. Stability test of the best performing catalyst $\mathrm{NiPS}_{3}-3 . \mathrm{oV}+\mathrm{P}$ in $1 \mathrm{M} \mathrm{KOH}$. 

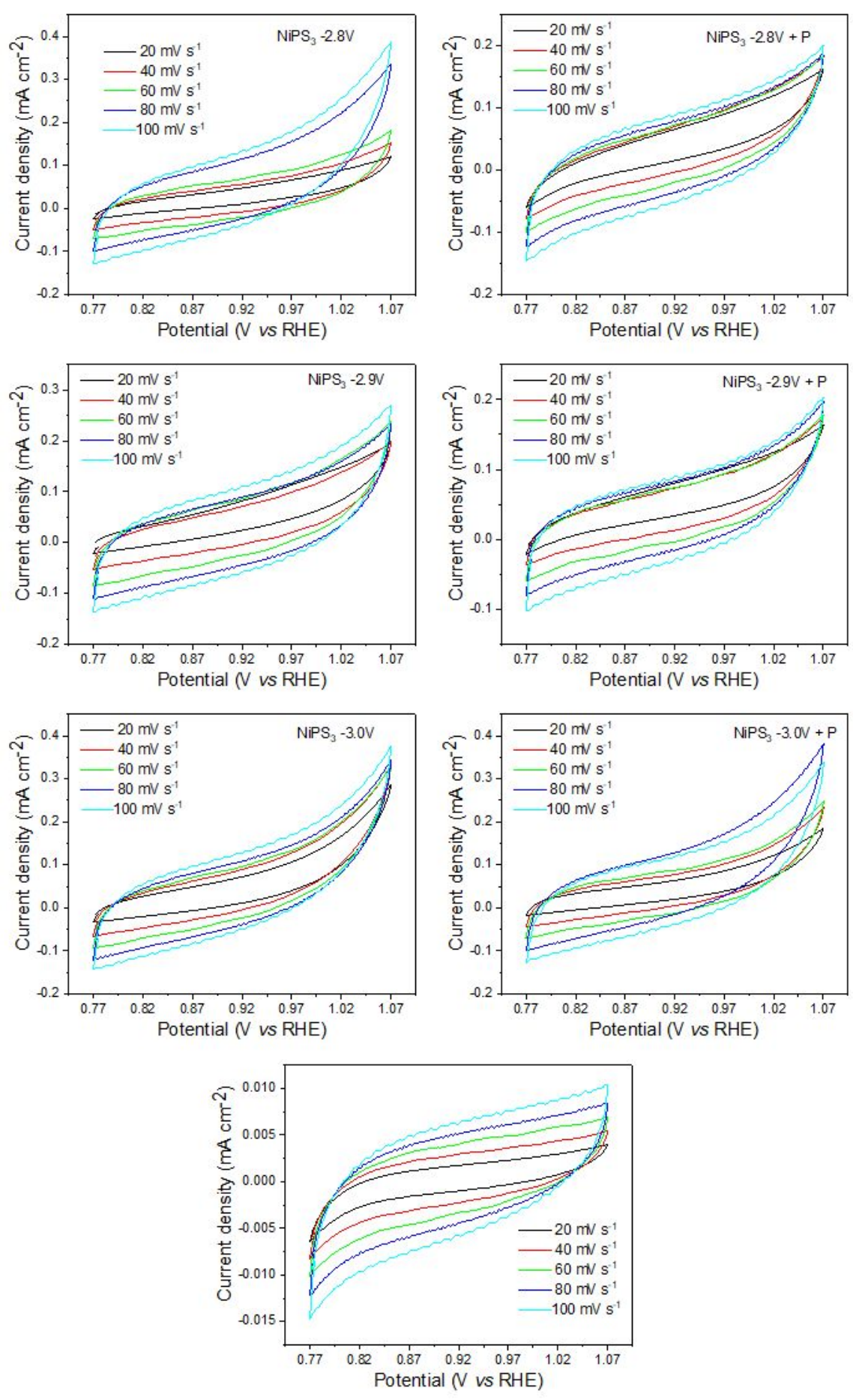

Figure S6. Cyclic voltammetry scan at various scan rates used for the calculation of double layer capacitance. 